\title{
Expectancy violation, reduction of food cue reactivity and less eating in the absence of hunger after one food cue exposure session for overweight and obese women
}

Citation for published version (APA):

Schyns, G., Roefs, A., Mulkens, S., \& Jansen, A. (2016). Expectancy violation, reduction of food cue reactivity and less eating in the absence of hunger after one food cue exposure session for overweight and obese women. Behaviour Research and Therapy, 76, 57-64.

https://doi.org/10.1016/j.brat.2015.11.007

Document status and date:

Published: 01/01/2016

DOI:

10.1016/j.brat.2015.11.007

Document Version:

Publisher's PDF, also known as Version of record

Document license:

Taverne

Please check the document version of this publication:

- A submitted manuscript is the version of the article upon submission and before peer-review. There can be important differences between the submitted version and the official published version of record. People interested in the research are advised to contact the author for the final version of the publication, or visit the DOI to the publisher's website.

- The final author version and the galley proof are versions of the publication after peer review.

- The final published version features the final layout of the paper including the volume, issue and page numbers.

Link to publication

\footnotetext{
General rights rights.

- You may freely distribute the URL identifying the publication in the public portal. please follow below link for the End User Agreement:

www.umlib.nl/taverne-license

Take down policy

If you believe that this document breaches copyright please contact us at:

repository@maastrichtuniversity.nl

providing details and we will investigate your claim.
}

Copyright and moral rights for the publications made accessible in the public portal are retained by the authors and/or other copyright owners and it is a condition of accessing publications that users recognise and abide by the legal requirements associated with these

- Users may download and print one copy of any publication from the public portal for the purpose of private study or research.

- You may not further distribute the material or use it for any profit-making activity or commercial gain

If the publication is distributed under the terms of Article 25fa of the Dutch Copyright Act, indicated by the "Taverne" license above, 


\title{
Expectancy violation, reduction of food cue reactivity and less eating in the absence of hunger after one food cue exposure session for overweight and obese women
}

\author{
Ghislaine Schyns*, Anne Roefs, Sandra Mulkens, Anita Jansen \\ Department of Clinical Psychological Science, Faculty of Psychology and Neuroscience, Maastricht University, P.O. Box 616, 6200 MD Maastricht, The \\ Netherlands
}

\section{A R T I C L E I N F O}

\section{Article history:}

Received 5 February 2015

Received in revised form

1 October 2015

Accepted 13 November 2015

Available online 30 November 2015

\section{Keywords:}

Food cue exposure

Extinction

Obesity

Cue reactivity

Eating in the absence of hunger

Body image

\begin{abstract}
A B S T R A C T
The present study investigated whether a single-session of food cue exposure for overweight women would decrease 'if CS then US' expectancies, cue reactivity and eating in the absence of hunger (EAH). EAH was measured in a behavioural paradigm that enabled to also investigate whether the cue exposure effects were specific for exposed foods or would generalise to food items that were not present during exposure. Overweight women were randomly assigned to either the cue exposure intervention or a control intervention that focused on body image. In line with the hypotheses, results showed that cue exposure induced a significant decrease in 'if CS then US' expectancies, in contrast to the control intervention. It was also found that, compared to the control intervention, desires to eat initially increased during cue exposure while gradual extinction was observed towards the end of the intervention. No extinction of increased salivation responses was found. Regarding EAH, the intake of the exposed food item was significantly less in the exposure condition than in the control condition, whereas total caloric food intake was not different between conditions, indicating that cue exposure was effective in reducing intake but did not generalise to the intake of other food items.
\end{abstract}

๑) 2015 Elsevier Ltd. All rights reserved.
Overweight and obesity prevalence's pose a serious problem worldwide. In the Unites States, more than two-third of the adult population is overweight of which approximately half is obese (Ogden, Carroll, Kit, \& Flegal, 2014). In European countries, as much as $50 \%$ of the adults population is overweight, including obesity prevalence's of $20 \%$ in men and $23 \%$ in women (WHO., 2014). Eating more than needed is primarily caused by hedonic eating or, put differently, eating for pleasure in the absence of (physiological) hunger (Lowe \& Butryn, 2007). A cause of eating in the absence of hunger (EAH) is increased reactivity to food cues (Jansen, Havermans, \& Nederkoorn, 2011a; Jansen et al., 2003). Food cue reactivity refers to anticipatory bodily reactions that prepare for food intake, such as saliva production, gastric activity and insulin rise, as well as psychological reactions such as a strong desire to eat the food (e.g. Jansen, 1998; Jansen et al., 2011a). Jansen (1998) theorized that most cue reactivity is classically conditioned. In classical conditioning, neutral stimuli (conditioned stimuli; CS) can

\footnotetext{
* Corresponding author.

E-mail address: ghislaine.schyns@maastrichtuniversity.nl (G. Schyns).
}

become associated with food intake (unconditioned stimulus; US) and, after a process of classical conditioning, just the confrontation with CSs can elicit conditioned responses (CR) as preparation for food digestion (Pavlov, 1927). With regard to human cue reactivity, stimuli such as the smell and sight of food (CS) that acquire predictive value of food intake (US) will easily elicit cue reactivity (CR), including increased eating desires and salivation (Jansen, 1998). Indeed, conditioning studies in animals and humans have found that after repeated pairings of neutral stimuli (CS) with food intake (US), CSs are able to elicit increased eating desires and bodily responses to prepare for food intake (e.g. salivation), and may stimulate overeating (e.g. Boggiano, Dorsey, Thomas, \& Murdaugh, 2009; Bouton, 2011; van den Akker, Havermans, \& Jansen, 2015; van den Akker, Havermans, Bouton, \& Jansen, 2014; van den Akker, Jansen, Frentz, \& Havermans, 2013). In line with these findings, it was found that healthy-weight non-restrained eaters showed increased gastric activity, heart rate and saliva production during exposure to food cues (CSs) (Nederkoorn \& Jansen, 2002).

According to Jansen's (1998) model, increased cue reactivity makes it harder to resist palatable food. This was indeed confirmed by a study in healthy-weight students, who received 10-min 
exposure to food cues, and on a separate day, a 10-min control task. Food intake was measured after both tasks. Results showed that students consumed more food after food exposure the control task (Jansen et al., 2011b). Ferriday and Brunstrom (2011) investigated cue reactivity and food intake in healthy-weight and overweight individuals, and found that one minute of food exposure led to increased desire to eat and food intake in both groups. However, food exposure led to significantly larger salivation and desire to eat in the overweight individuals as compared to the healthy-weight individuals. Along the same lines, a study that compared 10-min food exposure in overweight children versus healthy-weight children found that overweight children overate after food cue exposure, compared to healthy-weight children who successfully controlled their food intake. Moreover, food cue-induced salivary flow in the overweight children, and not in the healthy-weight children, was significantly positively related to food intake (Jansen et al., 2003). These findings show that exposure to food cues increases cue reactivity and food intake in healthy-weight participants - it is a normal response - while the effects are significantly stronger in overweight participants, making it more difficult for overweight people to resist tasty foods.

Circumstantial evidence for the hypothesis of cue reactivity playing a role in overeating comes from a pilot cue reactivity study in successful dieters (formerly obese) and unsuccessful dieters (still obese). The successful dieters had a current BMI $<25$, had achieved a mean weight loss of $27 \%$ of their original body weight and had maintained this weight loss for at least half a year, whereas unsuccessful dieters had a current BMI of $>30$ despite serious weight loss attempts. It was found that the unsuccessful dieters displayed a significant increase in salivation response to tasty food pictures relative to baseline salivation, whereas the successful dieters showed a significant decrease in salivation (Jansen, Stegerman, Roefs, Nederkoorn, \& Havermans, 2010). These findings suggest that successful refraining oneself from high-caloric foods eventually may result in decreased cue reactivity. As the authors suggested, decreased cue reactivity might, in turn, make it easier to resist foods and to maintain the weight loss. Reducing cue reactivity could therefore be helpful to lose weight and to successfully prevent relapse. In cue exposure, the clinical proxy of extinction, participants are exposed to non-reinforced CSs predicting US, in order to decrease cue reactivity (CR). For example, participants smell, touch and lick the tasty foods (CSs) while actual food intake (US) is not permitted. Some small clinical studies with bulimia nervosa patients suggest that cue exposure can be very effective in reducing food cravings and binge eating (Jansen, Broekmate, \& Heymans, 1992; Jansen, Van den Hout, De Loof, Zandbergen, \& Griez, 1989; Martinez-malle et al., 2007; Toro et al., 2003). A clinical study by Boutelle et al. (2011) showed that an 8-session cue exposure treatment in obese children and their parents was more effective to decrease EAH compared to an appetite awareness intervention. In another, 16-session intervention study in which cue exposure and appetite awareness components were combined, no direct effects after therapy were found on EAH compared to a no treatment control group, but significant lower EAH was found at follow-up (Boutelle et al., 2014). Though food cue exposure is a promising intervention that seems to be effective in reducing eating desires and $\mathrm{EAH}$, knowledge about its working mechanisms is still lacking.

It is now generally acknowledged that exposure therapy works through inhibitory learning (Craske et al., 2008; Craske, Liao, Brown, \& Vervliet, 2012). Though it was originally assumed that by exposure to the CS without the occurrence of the US, the original CS - US association could be destroyed, this appears not to be the case: extinction does not destroy the original CS - US bound, but creates a new learning pathway; the CS means that the US will not follow (CS - no US). In other words, the CS acquires two meanings:
CS means US and CS means no US (Bouton, 1993; Bouton \& King, 1983). Exposure should aim to make the new association (CS no US) stronger than the old association (CS - US). Exposure should therefore be designed to optimally learn the new CS - no US association, that is, the client learns that the US will probably not occur in the presence of the CS. This is also called CS - US expectancy violation (Craske et al., 2012; Craske, Treanor, Conway, Zbozinek, \& Vervliet, 2014). Craske et al. (2012; 2014) argue that CS - US expectancy violation during exposure is the key element for exposure to be effective: the more violation, the more treatment effect. This approach contrasts the habituation model, in which the central idea is to stay in the situation until fear (or in this case: the desire to eat) declines. Indeed, habituation either within and between exposure trials and ending fear levels have shown not to be a good predictor for treatment outcome (for review see Craske et al., 2008).

The primary aim of the present clinical experiment is to investigate whether food cue exposure is effective in reducing 'if CS then US' expectancies (i.e., expectancy violation), cue reactivity (saliva production and self-reported desires to eat), and eating in the absence of hunger (EAH) in overweight and obese females. 'If CS then US' expectancies are implicitly but not explicitly challenged in the present experiment. It is hypothesised that cue exposure significantly reduces 'if CS then US' expectancies, compared to the control condition (Rijkeboer \& Van den Hout, 2014). Regarding cue reactivity, it is expected that cue exposure significantly increases salivation and the desire to eat in the beginning of the exposure, followed by extinction during prolonged exposure. The cue exposure condition is further hypothesized to show less eating in the absence of hunger (EAH) compared to the control condition, both for the exposed food item chocolate mousse and total consumption (generalisation). Finally the role of habituation vs. inhibition learning regarding treatment outcome $(E A H)$ is investigated: EAH is expected to be positively associated with post-intervention 'if CS then US' expectations if inhibition learning is critical, whereas EAH is expected to be related to within-session habituation (WSH) of cue reactivity if habituation is critical for extinction.

\section{Method}

\subsection{Participants}

Participants who were motivated to lose weight were recruited via posters that were displayed in supermarkets and gyms. Fiftyfour overweight women (Body Mass Index > 25) aged between 18 and 65, who were not pregnant, and were able to smell, participated in this study. Participants were told that the study's aim was to investigate the effects of a single-session psychological training to cope with food temptations. Participants were randomly assigned to the cue exposure condition $(n=26)$ or the control condition $(n=28)$, by assigning the first six participants who could make it on the same intervention date to the cue exposure condition, the six next participants to the control condition, and so on. The study was approved by the Ethical Committee of the Faculty of Psychology and Neuroscience of Maastricht University.

\subsection{Assessment}

\subsection{1. 'If CS then US' expectancy}

The following 'if CS then US' statement for overeating was used: 'If I have tasty food in front of me, then I can not resist to eat it'. The believability of this statement at the present moment was rated on a 0 (not at all) to $100 \mathrm{~mm}$ (very strong) Visual Analogue Scale (VAS). 


\subsubsection{Desire to eat}

Desire to eat was measured by the statement: 'At the present moment, I have ... '. The statement was answered by rating a 0 (no desire at all to eat tasty food) to $100 \mathrm{~mm}$ (an extreme desire to eat tasty food) VAS. Desire to eat VASs are supposed to be valid measures of eating desires (e.g. Bongers, van den Akker, Havermans, \& Jansen, 2015; van den Akker et al., 2014; van den Akker et al., 2015; van den Akker et al., 2013).

\subsubsection{Hunger}

Current hunger was measured by the statement: 'At the present moment, I am ...' ', and answered by rating a 0 (not hungry at all) to $100 \mathrm{~mm}$ (very hungry) VAS.

\subsubsection{Salivation}

Salivation was measured by placing two dental cotton rolls (Hartmann, $\mathrm{nr} 2,10 \times 35 \mathrm{~mm}$ ) in the mouth between the cheek and left and right lower gums. The cotton rolls stayed in the mouth for exactly one minute. They were placed and removed by the participant and kept in a sealed plastic bag that was weighed before and after the measurement on a $0.01 \mathrm{~g}$ accurate weighing scale (Mettler Toledo, PB3002).

\subsubsection{EAH behavioural paradigm}

The EAH paradigm was adapted from the paradigm described by Birch and Fisher (2000). In the present study, each participant received two standard pre-packed sandwiches that she was required to eat, to induce a state of satiation (absence of hunger). A questionnaire on taste and quality was provided together with the sandwiches, as a first part of the bogus taste test. After finishing the sandwiches, participants waited for $15 \mathrm{~min}$ to achieve a satiated state. Before and $15 \mathrm{~min}$ after the required standard meal, current hunger was measured. Directly after the post meal hunger rating, a 10-min bogus taste test of 6 desserts started. Participants were told that this test was to assess taste perception of six different food items. Participants were instructed to rate the taste of each of the 6 desserts (using a questionnaire) while being allowed to eat as much as they wanted from the generous portions of each food item: chocolate mousse ( $\sim 80 \mathrm{~g} / \sim 142 \mathrm{kcal}$; Almhof), whipped cream ( 90 g/ 165 kcal; Campina), muffin ( $80 \mathrm{~g} / \sim 262 \mathrm{kcal}$; Jumbo supermarket), custard ( 190 g/ 173 kcal; Campina), strawberry mousse $(\sim 120 \mathrm{~g} / \sim 156 \mathrm{kcal}$; Dr. Oetker), chocolate cake $(\sim 80 \mathrm{~g} /$ $\sim 330 \mathrm{kcal}$; Coolmore). The total plate of desserts consisted of roughly $1230 \mathrm{kcal}$. The taste test was done individually; tables were separated by large screens. After the bogus taste test, foods were removed. Each food item was weighed before and after the taste test, and the number of consumed kcal was calculated.

\subsubsection{Expectation and evaluation of the intervention}

Each participant rated pre- and post intervention how much she expected to learn/had learned from the intervention on a 5-point scale from 1 (not at all) to 5 (very much) and whether she expected the intervention to help her gaining control over eating, rated from 1 (much less control) to 5 (much more control).

\subsubsection{Body satisfaction}

Body satisfaction was measured with the statement: 'At the present moment, I am ... '. The statement was answered by rating a 0 (very dissatisfied with my body) to $100 \mathrm{~mm}$ (very satisfied with my body) VAS. Body satisfaction VASs have been used in previous studies (e.g. Jansen et al., 2016).

\subsubsection{Pre-intervention intake}

At the intervention day, participants were asked to report at what time they had eaten their last meal (breakfast or snack) and what this meal consisted of.

\subsubsection{BMI}

To calculate BMI $\left(\mathrm{kg} / \mathrm{m}^{2}\right)$, height and weight ( $0.1 \mathrm{~kg}$ accurate; My Weigh, XL-550), were measured in the laboratory by the experimenter.

\subsubsection{Awareness check}

It was checked whether the participant was aware of the aim of the bogus taste test and study by means of an open question.

\subsection{Procedure}

Participants gave informed consent, filled out some demographic questions and the favourite food list to determine individualized cue exposure foods online. In order to keep the food appealing during the entire session, warmly prepared foods were not selected as cue exposure foods. The participants were randomly assigned to the cue exposure or the control condition.

Interventions were provided in a group of minimally 3 and maximally 7 participants $(M=4.5$ participants per group; 12 groups in total). Interventions took place on weekdays from 9.30am to $1.30 \mathrm{pm}$. Participants were instructed to eat a regular breakfast, but no snacks between breakfast and the intervention. Because of practical considerations, two groups ( 1 cue exposure and 1 control) took place in the afternoon from 13.30 to $17.30 \mathrm{pm}$. For these participants the instruction was to eat a regular lunch, but no snacks between lunch and the intervention.

After arrival in the laboratory, baseline measurements were done (saliva, pre-intervention intake assessment, and VASs: desire to eat, hunger, body satisfaction, the believability of the 'if CS then US' expectancy statement). Then participants were given a short rational behind the intervention they would receive. They rated their expectancy of the intervention, after which the intervention started (see detailed description of interventions below). Both interventions lasted exactly $80 \mathrm{~min}$, with breaks in between. In the cue exposure condition, there were three 10 -min breaks after every 20 min of exposure, while there was one 30 -min break after 40 min in the control condition. Saliva was measured at 13 time-points (at baseline and 12 times during the intervention). Desire to eat was also measured at the same 13 time-points as well as twice after the intervention: before the sandwich meal (BM) and after the meal (AM). In the cue exposure condition, 16 additional desire to eat measurements were taken throughout the intervention, including 4 measurements (minutes $0,20,40,60$ ) when exposure foods were not visible. The timer was stopped for interruptions due to the measurements (e.g. placing and removing cotton roles, filling out VASs), resulting in $80 \mathrm{~min}$ of pure intervention. Eating was not allowed during the interventions and breaks. After the intervention, participants again rated desire to eat, hunger and body dissatisfaction, as well as the believability of the 'if CS then US' expectancy statement. Then the two-sandwich meal was eaten, with coffee or tea, followed by a 15 min break and the bogus taste test. Thereafter participants completed the awareness check and participants were weighed and their height was measured. They were thanked for participation and debriefed about the nature of the study, after which they received $€ 25$ for participation. All sessions were audiotaped. An overview of the timing of assessments is displayed in Fig. 1.

\subsubsection{Cue exposure intervention}

Each participant received their individualized top four favourite food items that were continuously available right in front of them on a tray. Every participant was also exposed to chocolate mousse. Participants were coached in getting their desire to eat the food as 


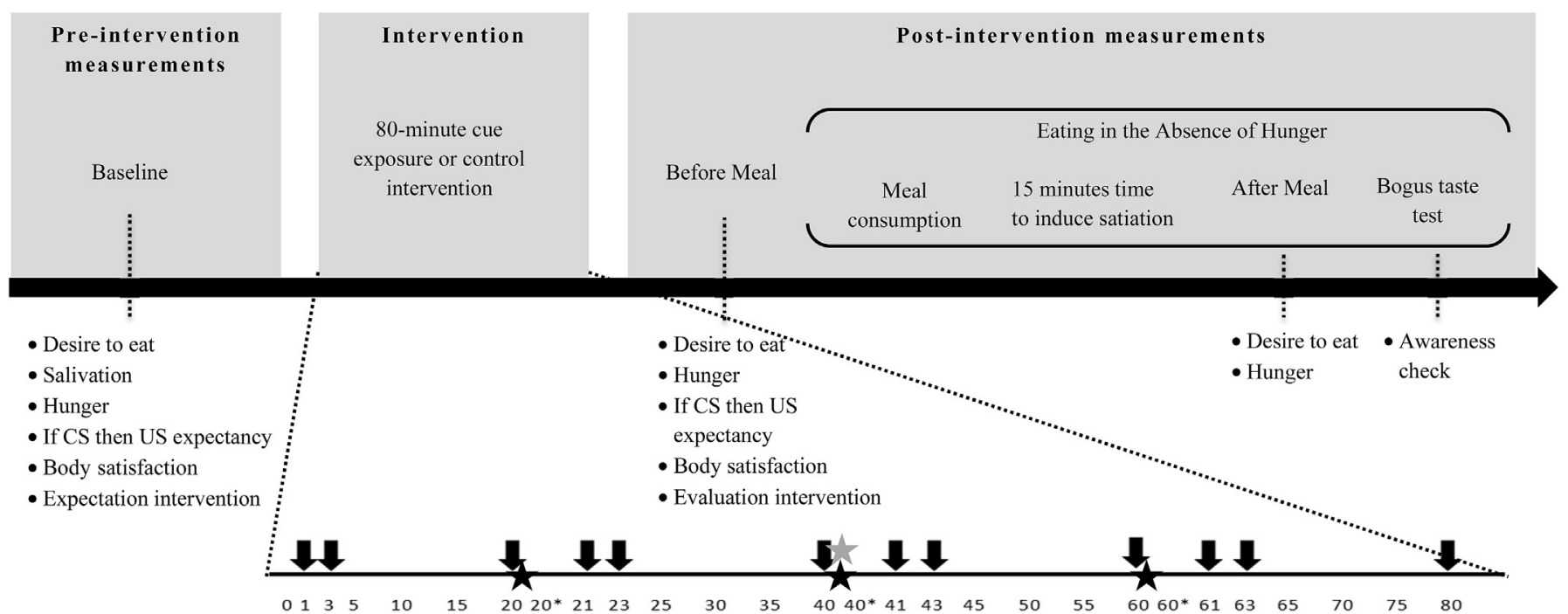

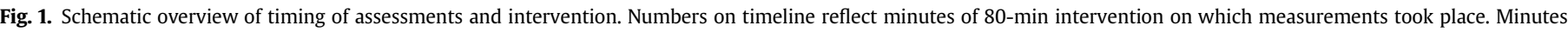

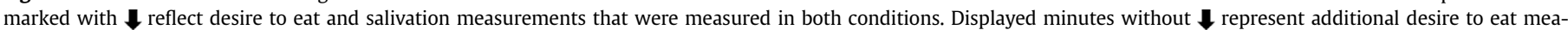

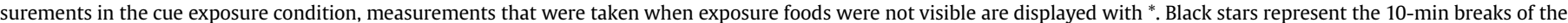
cue exposure condition, the grey star represents the 30-min break of the control condition.

high as possible, by smelling (directly under the nose), feeling, licking and imagining eating the food, but consumption was not allowed. Large portions of food were provided, not only to maximise visual and olfactory stimulation, but also in order to have appealing food available during the entire session. For example, several chocolate bars were provided in case the chocolate melted during exposure. During the breaks, tea towels were placed over the food trays. After $80 \mathrm{~min}$ of food cue exposure, each participant threw away all her foods in a garbage bin.

\subsubsection{Control intervention}

The aim of the control intervention was to increase body satisfaction, by discussing topics such as the beauty ideal, media literacy and fat talk. The experimenter presented scientific studies and experiments, followed by assignments for the participants that were discussed in the group afterwards. An example of an assignment was to write down the feelings that came up while looking at pictures of healthy-weight and underweight models.

\section{Results}

\subsection{Descriptives}

The mean age of the sample was 44.65 years $(S D=10.91$, range $=21-61$ ) with no differences between conditions, $t(52)=1.13, p=.264$. The cue exposure condition $(M=33.89$, $S D=5.37$, range: 25.7-52.5) had a significantly higher BMI (measured in the laboratory) than the control condition $(M=30.85$, $S D=3.45$, range: $25.6-37.5), t(52)=2.49, p=.016$. Including BMI as a covariate was however not a significant contributor for any of the outcome measures, nor was the interaction between group and BMI significant for any of the outcome measures. BMI was therefore not included in the analyses below.

\subsection{Credibility of the interventions}

The mean expectation and evaluation of the intervention on how much will be learned/was learned was equal in the cue exposure condition (pre-intervention: $M=3.46, S D=0.58$; post- intervention: $M=3.42, S D=0.90)$ and the control condition (pre-intervention: $M=3.54, S D=0.79$; post-intervention: $M=3.29, S D=0.94), t(52)=0.39, p=.699$ and $t(52)=0.55$, $p=.586$ respectively. Regarding control over eating, participants receiving cue exposure (cue exposure: $M=4.23, S D=0.59$ ) had marginally significant higher expectations that the intervention would help them gain control over eating compared to the control condition $(M=3.93, S D=0.54) ; t(52)=1.97, p=.054$. The evaluation scores indicated that, after the intervention, participants rated the cue exposure intervention $(M=4.04, S D=0.53)$ as more helpful in gaining control over eating compared to the control condition $(M=3.71, S D=0.53), t(52)=2.24, p=.029$.

Lastly, as the control intervention aimed to increase body satisfaction, an ANCOVA was conducted with post-intervention body satisfaction score as dependent variable, condition (cue exposure, control) as independent variable, and pre-intervention body satisfaction score as covariate. Though both conditions scored equal at pre-intervention on the body satisfaction scale (cue exposure: $M=34.00, S D=23.95$; control: $M=33.54, S D=20.71$ ), post-intervention body satisfaction of the control condition $(M=57.54, S D=19.41)$ was significantly higher than postintervention body satisfaction of the cue exposure condition $(M=39.58, S D=24.63)$, indicating that the control intervention was successful in increasing body satisfaction, $F(1,51)=14.64$, $p<.001$.

\section{3. 'If CS then US' expectancy}

As can be seen in Fig. 2, both conditions scored equal on the 'if CS then US' expectancy scale at pre-intervention $(F<1)$ while at postintervention the cue exposure condition, in contrast to the control condition, believed significantly less in the 'if CS then US' expectancy statement while controlling for pre-intervention 'if CS then US' expectancy in an ANCOVA, $F(1,50)=4.16, p=.047$. These findings indicate that the cue exposure intervention was effective in expectancy violation while the control intervention was not; after cue exposure one's belief in loss of control when confronted with tempting foods was significantly reduced. 


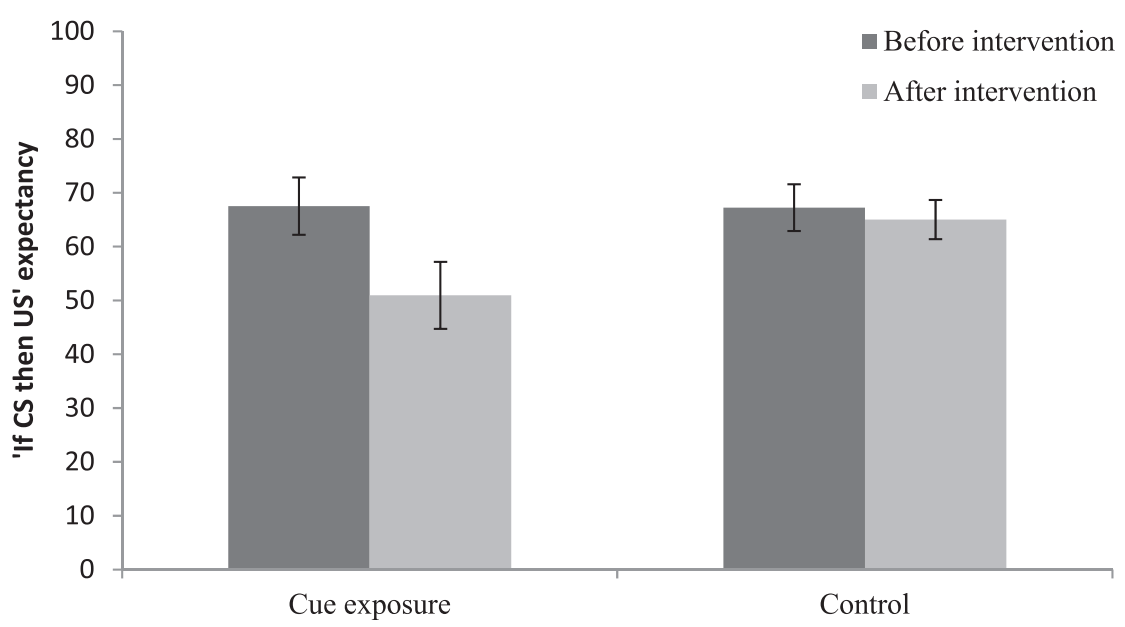

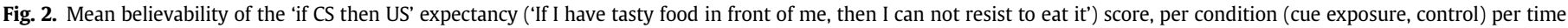
point (before intervention, after intervention). Error bars represent standard errors of means.

\subsection{Cue reactivity}

As can be seen in Figs. 3 and 4, cue reactivity was indeed established: desire to eat and salivation increased significantly over time in the cue exposure condition compared to the control condition. This was confirmed by a 2 (condition: cue exposure, control) x 13 (time: baseline, $1^{\prime}, 3^{\prime}, 20^{\prime}, 21^{\prime}, 23^{\prime}, 40^{\prime}, 41^{\prime}, 43^{\prime}, 60^{\prime}, 61^{\prime}, 63^{\prime}, 80^{\prime}$ ) repeated measures ANOVA for desire to eat, in which a significant condition $\times$ time interaction was found, $F(12,41)=4.68, p<.001$. To examine whether extinction took place at the end of the intervention, an ANCOVA was performed to compare conditions on desire to eat at minute 80 while controlling for baseline desire to eat. Results showed that conditions did not differ anymore on desire to eat at the end of the intervention, $F(1,51)=1.03, p=.314$, indicating that extinction of the desire to eat in the exposure condition was successful. In addition, within-session habituation (WSH) was calculated, as operationalised by subtracting the endlevel of cue reactivity from the peak response during the intervention (Craske et al., 2008). In line with the end level of desire to eat, WSH was significantly greater for the cue exposure condition $(M=2.15, S D=2.14)$ compared to the control condition $(M=0.70$, $S D=1.59), t(52)=2.80, p=.007$.

The extinction of the desire to eat in the cue exposure condition was also found right after the end of the intervention, but before the meal started (BM). The 2 (condition) x 2 (time: 80', BM) repeated measures ANOVA on desire to eat showed a significant condition $\times$ time interaction, $F(1,52)=11.96, p=.001$. Just before the meal started, a significant drop in desire to eat was observed in the cue exposure condition, while a steep increase in desire to eat was observed in the control condition (see Fig. 3).

The other cue reactivity measure, salivation (Fig. 4), was also analysed in a $2 \times 13$ repeated measures ANOVA and showed a marginally significant condition $\times$ time interaction effect, $F(12,38)=1.83, p=.077$, as well as a significant main effect of condition, $F(1,49)=4.38, p=.042$. Thus, though salivation responses were similar at baseline $(F<1)$, the cue exposure condition salivated significantly more than the control condition throughout the intervention. The main effect of time on salivation was not significant $(F<1)$ indicating that salivation responses remained stable over $80 \mathrm{~min}$ of intervention for both conditions. An ANCOVA on minute 80 with baseline salivation as covariate showed that participants in the exposure condition still salivated significantly more at the end of the intervention compared to the control condition, $F(1,51)=4.55, p=.038$. In line with the end level of salivation, WSH was equal for cue exposure condition $(M=0.36$, $S D=0.43)$ as for to the control condition $(M=0.21, S D=0.16)$, $t(52)=1.62, p=.112$.

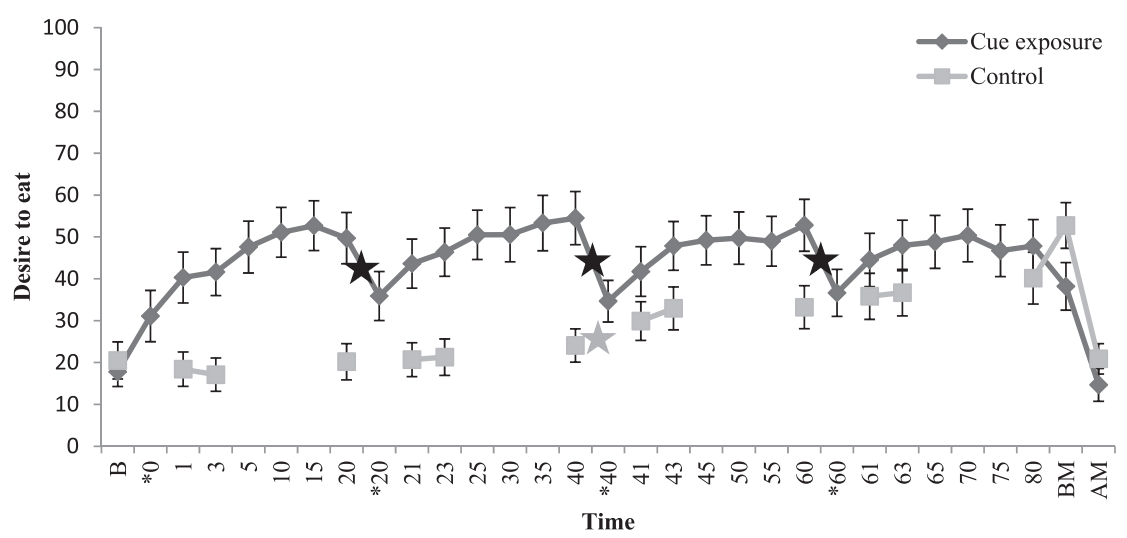

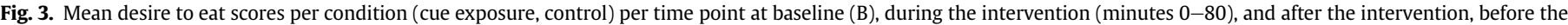

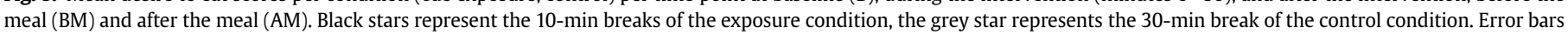
represent standard errors of means. Additional measurements in the cue exposure condition that were taken when exposure foods were not visible are displayed with *. 


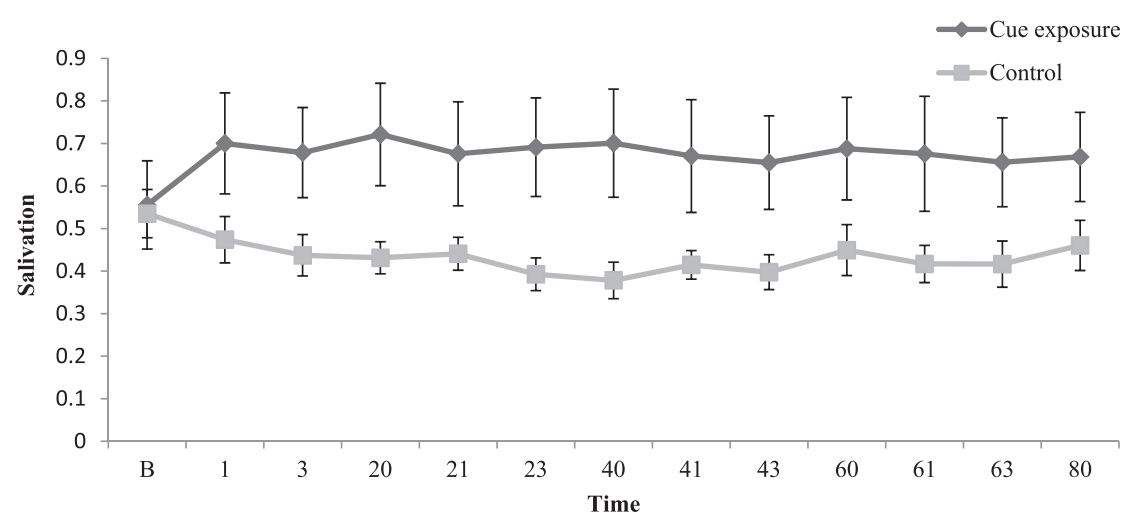

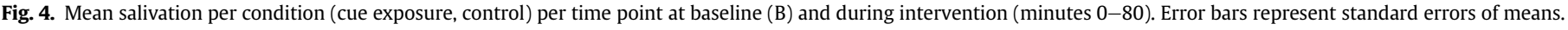

\section{5. $E A H$}

All participants followed the instruction of eating a breakfast or lunch and no additional snacks before the intervention. Based on post-meal hunger ratings, six participants were excluded from the behavioural EAH analyses: five reported still being hungry after the meal (defined as score $>50 \mathrm{~mm}$ on the $100-\mathrm{mm}$ VAS), and one person had a missing value on post-meal hunger. Further, two additional participants had to be excluded from the analyses because they did not receive chocolate mousse during exposure due to a practical error, ending up with 46 participants $(n=21$ cue exposure, $n=25$ control). Post-meal hunger ratings did not differ between conditions (cue exposure: $M=9.48, S D=9.15$; control: $M=11.38, S D=11.14), t(44)=-0.63, p=.535$, indicating that the absence of hunger manipulation succeeded. Participants whose answers on the awareness check suggested they were more or less aware of the aim of the bogus taste test $(n=11)$ were equally divided over the conditions, $\chi^{2}(1,46)=0.50, p=.478$, and they did not consume less kcal in total than participants who were not at all aware, $t(44)=0.15, p=.881$, therefore these participants were not excluded from the analyses.

In order to examine to effect of cue exposure on EAH, two separate tests were performed. As chocolate mousse was an exposure item for every participant, chocolate mousse intake during EAH was analysed separately from the other food items to examine specific effects of food cue exposure. In addition, total intake during EAH (without chocolate mousse) was analysed as an indication of the generalisability of exposure effects.

\subsubsection{Total intake}

Means and SDs for consumed kcal during the bogus taste test are displayed in Table 1 . Total kcal consumption (without chocolate mousse) was equal for both conditions, $t(44)=-0.71, p=.480$.

\subsubsection{Chocolate mousse intake}

The cue exposure condition consumed significantly less

\section{Table 1}

Means and standard deviations (SD) of kcal consumed during EAH paradigm, separated by condition (cue exposure, control).

\begin{tabular}{|c|c|c|}
\hline & Cue exposure & Control \\
\hline & $n=21$ & $n=25$ \\
\hline Total kcal ${ }^{1}$ & $217.44(125.18)$ & $246.53(147.75)$ \\
\hline Kcal chocolate mousse ${ }^{2^{*}}$ & $22.13(17.42)$ & $39.65(31.55)$ \\
\hline
\end{tabular}

1. Total kcal intake (of all desert items excluding chocolate mousse) during taste test in EAH paradigm. 2. Kcal intake of chocolate mousse (i.e., food that was part of cue exposure intervention) during taste test in EAH paradigm. ${ }^{*} \mathrm{p}<.05$. chocolate mousse compared to the control condition, $t(44)=-2.38, p=.022$. See Table 1 for means and SDs.

Finally, correlations between intake and WSH of cue reactivity, as well as between intake and if CS then US expectancies were calculated. Regarding the cue reactivity-intake association, neither WSH of desire to eat nor WSH of salivation were significantly correlated with total kcal intake, $r(46)=-0.03, p=.828$, resp. $r(46)=-0.16, p=.281$, or chocolate mousse kcal intake, $r(46)=-0.21, p=.167$, resp. $r(46)=-0.23, p=.131$. Regarding the 'if CS then US' expectancy-intake association, a significant positive correlation was found between chocolate mousse intake and postintervention 'if CS then US' expectancy, $r(46)=0.34, p=.022$, indicating that lower CS - US expectancies were associated with less chocolate mousse intake. The correlation between 'if CS then US' expectancy and total kcal intake was not significant, $r(46)=0.07, p=.665$. Thus, chocolate mousse intake was positively associated post-intervention 'if CS then US' expectancies, while chocolate mousse intake was not associated with WSH of cue reactivity.

\section{Discussion}

In the present study, food cue exposure induced, compared to a control intervention, a significant decrease of the expectancy not to be able to resist tempting foods when confronted with them, an initial increase of cue reactivity (eating desires and salivation) during the intervention, followed by extinction of eating desires at the end of the intervention, and less eating in the absence of hunger of the exposed food item (i.e. chocolate mousse). In addition, a significant positive correlation was found between postintervention 'if CS then US' expectancy and chocolate mousse intake while chocolate mousse intake did not correlate with within-session habituation (WSH) of cue reactivity.

Consistent with our hypothesis, it was found that 'if CS then US' expectancies significantly decreased during cue exposure while they did not change during the control intervention. This means that a central dysfunctional cognition associated with overeating ('If I have tasty food in front of me, then I can not resist eating it') can be changed in a single-session food cue exposure, though this cognition was not explicitly challenged during the exposure.

Recent recommendations from Craske and colleagues state that exposure is most effective when 'if CS then US' expectancies are violated (Craske et al., 2012, 2014). Exposure sessions should be designed in a way that US expectancies are maximally violated: strong, frequent and repeated violation of expectancies would improve and strengthen the learning of inhibitory CS - no US associations (Craske et al., 2014). For example, the length of an 
exposure session could be determined by the time needed for the US to be expected, instead of waiting until fear (or craving) levels have significantly decreased. In line with this, it has been found that continuing interoceptive exposure for panic disorder until US expectancies decline under $5 \%$ is more effective than standard interoceptive exposure (Deacon et al., 2013). Likewise, food cue exposure might be most effective when sessions are tailored on individual US expectancies; a session ends when the individual's belief "If I have tasty food in front of me, then I can not resist eating it" is lower than $5 \%$, instead of aiming at decreased desires to eat or other cue reactivity. In the present study, the 'if CS then US' belief significantly reduced during cue exposure but still was around $50 \%$ at the end of the exposure. It is of interest to study whether aiming more specifically at a drop of the 'if CS then US' expectancy to less than $5 \%$, will lead to a generalisation of the current EAH effects to other food items.

An increase in cue reactivity during the start of the intervention was found for both self-reported desire to eat and salivation but only extinction of the self-reported desire to eat was found. The final part of the intervention took place close to lunch time and all participants were explicitly told that a lunch followed the intervention. That the desire to eat at the end of the intervention did not differ anymore between conditions indicates that extinction took place, as the cue exposure participants were still intensely exposed to their favourite food items. Remarkable was the sudden drop in desire to eat in the cue exposure condition after the intervention: while the control condition reported an increased desire to eat just before lunch, the exposure condition reported a decrease in desire to eat. Although all participants expected a lunch, eating desires elicited by food cue exposure might be very specific: participants might have had a strong desire to eat the snack foods they were exposed to, while they did not desire to eat regular lunch foods.

Unexpectedly, extinction of the increased salivation response was not found, as mean salivation remained higher for the cue exposure condition during the entire intervention. It is possible that a salivation extinction effect needs more sessions. In a laboratory conditioning study by Van Gucht et al. (2008) decreased salivation was not observed in a first extinction session, while it was marginally lower in the second extinction session.

Another aim of the present study was to investigate whether a one-session cue exposure intervention decreases EAH, and whether the hypothesized decreased intake is specific for exposed food items or whether it would generalise to other food items that were not present during exposure. Indeed, the intake of the one exposure food item (chocolate mousse) was significantly lower in the exposure condition compared to the controls. Total consumption did however not significantly differ between conditions. These data show that inhibitory learning takes place during one session of food cue exposure as participants could successfully inhibit themselves when confronted with an exposed food item, though the inhibitory learning did not generalise to food items that were not present during the cue exposure. It is of interest to further study whether generalisation of inhibition learning in eating is facilitated by sleep, since fear extinction studies have shown better generalisation after a good sleep, which is explained by improved consolidation of extinction memories during sleeping (Kleim et al., 2014; Pace-Schott, Verga, Bennett, \& Spencer, 2012; Spoormaker et al., 2012, 2010).

The correlational data show that a weaker belief in the 'If CS then US' expectancy is significantly associated with less chocolate mousse intake, while neither WSH of self-reported desires nor WSH of salivation where correlated to food intake. This finding supports the importance of inhibitory learning (if CS no US) during food cue exposure and suggests it is more important to focus on the inhibitory learning than aiming at decreased cue reactivity, which is also true for anxiety (Craske et al., 2008). Lower fear levels at the end of an exposure session do not lead to better outcomes, and even quitting exposure at the highest fear level results in equal treatment effects compared to prolonged exposures until fear declines (Rachman, Craske, Tallman, \& Solyom, 1986; Rachman, Robinson, \& Lopatka, 1987).

A limitation of the present study is the lack of long term followup. Although the aim of the study was to investigate within-session mechanisms, measuring outcome later in time, considering the previous point on consolidation due to sleep, might have been very interesting and should be considered in future studies. In addition, the used 'if CS then US' believability rating has not been used in previous research before. It is possible that this specific cognition was not as relevant for every participant, whereas personalized 'if CS then US' statements might better capture individual learning processes during exposure.

To conclude, the single food cue exposure session in the present study was effective in decreasing desires to eat and caloric intake of the exposed food item. Adding exposure to obesity treatment could therefore be a highly valuable component. In addition, food cue exposure also reduced 'if CS then US' expectancies, and this expectancy violation was associated with less eating of the cued food in the absence of hunger. Interestingly, habituation of the desire to eat and salivation was not at all related to intake. A clear parallel can be drawn to clinical recommendations from the anxiety literature (e.g. Craske et al., 2014): though desires to eat might be an important motivation to start exposure therapy, within-session desires should not be taken as a reference for learning. Instead, focussing on the inhibitory learning by explicitly tackling and violating verbalised CS-US expectancies during therapy might be more important for treatment success, also in overeaters and obesity.

\section{Conflict of interest}

The authors report no conflict of interest.

\section{Acknowledgements}

This study is part of an ongoing project that is financed by the Netherlands Organisation for Scientific Research (NWO): Vici Grant 453.10.006, awarded to Anita Jansen. The authors would like to thank Jessica Alleva for her help in composing the control intervention program and Jette Spoormans for her help in collecting data. Further, the authors would like to thank Infraligne studio Maastricht for notifying clients about the study.

\section{References}

Birch, L. L., \& Fisher, J. O. (2000). Mothers' child-feeding practices influence daughters' eating and weight. The American Journal of Clinical Nutrition, 71, 1054-1061.

Boggiano, M. Dorsey, J. Thomas, J. \& Murdaugh, D, (2009). The Pavlovian power of palatable food: lessons for weight-loss adherence from a new rodent model of cue-induced overeating. International Journal of Obesity, 33(6), 693-701.

Bongers, P., van den Akker, K., Havermans, R., \& Jansen, A. (2015). Emotional eating and Pavlovian learning: does negative mood facilitate appetitive conditioning? Appetite, 89, 226-236.

Boutelle, K. N., Zucker, N. L., Peterson, C. B., Rydell, S. a., Cafri, G., \& Harnack, L. (2011). Two novel treatments to reduce overeating in overweight children: a randomized controlled trial. Journal of Consulting and Clinical Psychology, 79, 759-771. http://dx.doi.org/10.1037/a0025713.

Boutelle, K. N., Zucker, N., Peterson, C. B., Rydell, S., Carlson, J., \& Harnack, L. J. (2014) An intervention based on Schachter's externality theory for overweight children: the regulation of cues pilot. Journal of Pediatric Psychology, 39, 405-417. http://dx.doi.org/10.1093/jpepsy/jst142.

Bouton. M. E. (1993). Context, time, and memory retrieval in the interference paradigms of Pavlovian learning. Psychological Bulletin, 114(1), 80-99.

Bouton, M. E. (2011). Learning and the persistence of appetite: extinction and the motivation to eat and overeat. Physiology \& Behavior, 103(1), 51-58. http://dx. 
doi.org/10.1016/j.physbeh.2010.11.025.

Bouton, M. E. \& King. D. A. (1983). Contextual control of the extinction of conditioned fear: tests for the associative value of the context. Journal of Experimental Psychology: Animal Behavior Processes, 9(3), 248-265.

Craske, M. G., Kircanski, K., Zelikowsky, M., Mystkowski, J., Chowdhury, N., \& Baker, A. (2008). Optimizing inhibitory learning during exposure therapy. Behaviour Research and Therapy, 46(1), 5-27. http://dx.doi.org/10.1016/j.brat. 2007.10.003.

Craske, M. G., Liao, B., Brown, L., \& Vervliet, B. (2012). The role of inhibition in exposure therapy. Journal of Experimental Psychopathology, 3(3), 322-345. http://dx.doi.org/10.5127/jep.026511.

Craske, M. G., Treanor, M., Conway, C. C., Zbozinek, T., \& Vervliet, B. (2014). Maximizing exposure therapy: an inhibitory learning approach. Behaviour Research and Therapy, 58, 10-23. http://dx.doi.org/10.1016/j.brat.2014.04.006.

Deacon, B., Kemp, J. J., Dixon, L. J., Sy, J. T., Farrell, N. R., \& Zhang, A. R. (2013). Maximizing the efficacy of interoceptive exposure by optimizing inhibitory learning: a randomized controlled trial. Behaviour Research and Therapy, 51, 588-596. http://dx.doi.org/10.1016/j.brat.2013.06.006.

Ferriday, D., \& Brunstrom, J. M. (2011). 'I just can't help myself': effects of food-cue exposure in overweight and lean individuals. International Journal of Obesity (2005), 35, 142-149. http://dx.doi.org/10.1038/ijo.2010.117.

Jansen, A. (1998). A learning model of binge eating: cue reactivity and cue exposure. Behaviour Research and Therapy, 36, 257-272.

Jansen, A., Broekmate, J., \& Heymans, M. (1992). Cue-exposure vs self-control in the treatment of binge eating: a pilot study. Behaviour Research and Therapy, 30, 235-241.

Jansen, A., Havermans, R., \& Nederkoorn, C. (2011a). Cued overeating. In V. R. Preedy, R. R. Watson, \& C. R. Martin (Eds.), The international handbook of behavior, diet and nutrition (pp. 1431-1443). New York: Springer.

Jansen, A., Nederkoorn, C., Roefs, A., Bongers, P., Teugels, T., \& Havermans, R. (2011b). The proof of the pudding is in the eating: is the DEBQ-external eating scale a valid measure of external eating? The International Journal of Eating Disorders, 44, 164-168. http://dx.doi.org/10.1002/eat.20799.

Jansen, A., Stegerman, S., Roefs, A., Nederkoorn, C., \& Havermans, R. (2010) Decreased salivation to food cues in formerly obese successful dieters. Psychotherapy and Psychosomatics, 79, 257-258. http://dx.doi.org/10.1159/ 000315131.

Jansen, A., Theunissen, N., Slechten, K., Nederkoorn, C., Boon, B., Mulkens, S., et al. (2003). Overweight children overeat after exposure to food cues. Eating Behaviors, 4, 197-209. http://dx.doi.org/10.1016/S1471-0153(03)00011-4.

Jansen, A., Van den Hout, M. A., De Loof, C., Zandbergen, J., \& Griez, E. (1989). A case of bulimia successfully treated by cue exposure. Journal of Behavior Therapy and Experimental Psychiatry, 20(4), 327-332.

Jansen, A., Voorwinde, V., Hoebink, Y., Rekkers, M., Martijn, C. \& Mulkens, S. (2016). Mirror exposure to increase body satisfaction: should we guide the focus of attention towards positively or negatively evaluated body parts? Journal of Behavior Therapy and Experimental Psychiatry, 50, 90-96.

Kleim, B., Wilhelm, F., Temp, L., Margraf, J., Wiederhold, B., \& Rasch, B. (2014). Sleep enhances exposure therapy. Psychological Medicine, 44(07), 1511-1519. http:// dx.doi.org/10.1017/S0033291713001748.

Lowe, M. R., \& Butryn, M. L. (2007). Hedonic hunger: a new dimension of appetite? Physiology \& Behavior, 91(4), 432-439. http://dx.doi.org/10.1016/j.physbeh.
2007.04.006.

Martinez-malle, E., Castro-fornieles, J., La, L., Moreno, E., Morer, A., Font, E., et al. (2007). Cue exposure in the treatment of resistant adolescent bulimia nervosa. http://dx.doi.org/10.1002/eat.

Nederkoorn, C., \& Jansen, A. (2002). Cue reactivity and regulation of food intake. Eating Behaviors, 3, 61-72.

Ogden, C. L., Carroll, M. D., Kit, B. K., \& Flegal, K. M. (2014). Prevalence of childhood and adult obesity in the United States, 2011-2012. JAMA, 311(8), 806-814. http://dx.doi.org/10.1001/jama.2014.732.

Pace-Schott, E. F., Verga, P. W., Bennett, T. S., \& Spencer, R. M. C. (2012). Sleep promotes consolidation and generalization of extinction learning in simulated exposure therapy for spider fear. Journal of Psychiatric Research, 46, 1036-1044. http://dx.doi.org/10.1016/j.jpsychires.2012.04.015.

Pavlov, I. P. (1927). Conditioned reflexes. London: Oxford University Press.

Rachman, S., Craske, M., Tallman, K., \& Solyom, C. (1986). Does escape behavior strengthen agoraphobic avoidance? A replication. Behavior Therapy, 17(4) 366-384. http://dx.doi.org/10.1016/S0005-7894(86. http://dx.doi.org/10.1016/ S0005-7894(86)80069-7.

Rachman, S., Robinson, S., \& Lopatka, C. (1987). Is incomplete fear-reduction followed by a return of fear? Behaviour Research and Therapy, 25(1), 67-69. http: / dx.doi.org/10.1016/0005-7967(87. http://dx.doi.org/10.1016/0005-7967(87) 90116-1.

Rijkeboer, M. M., \& Van den Hout, M. A. (2014). Nieuwe inzichten over exposure Gedragstherapie, 47(1).

Spoormaker, V. I., Schröter, M. S., Andrade, K. C., Dresler, M., Kiem, S. A., GoyaMaldonado, R., et al. (2012). Effects of rapid eye movement sleep deprivation on fear extinction recall and prediction error signaling. Human Brain Mapping, 33(10), 2362-2376. http://dx.doi.org/10.1002/hbm.21369.

Spoormaker, V. I., Sturm, A., Andrade, K., Schröter, M., Goya-Maldonado, R. Holsboer, F., et al. (2010). The neural correlates and temporal sequence of the relationship between shock exposure, disturbed sleep and impaired consolidation of fear extinction. Journal of Psychiatric Research, 44(16), 1121-1128. http://dx.doi.org/10.1016/j.jpsychires.2010.04.017.

Toro, J., Cervera, M., Feliu, M. H., Garriga, N., Jou, M., Martinez, E., et al. (2003). Cue exposure in the treatment of resistant bulimia nervosa. The International Journal of Eating Disorders, 34, 227-234. http://dx.doi.org/10.1002/eat.10186.

Van Gucht, D., Vansteenwegen, D., Beckers, T. Hermans, D., Baeyens, F., \& Van den Bergh, O. (2008). Repeated cue exposure effects on subjective and physiological indices of chocolate craving. Appetite, 50, 19-24. http://dx.doi.org/10.1016/ j.appet.2007.05.003.

van den Akker, K., Havermans, R. C., Bouton, M. E., \& Jansen, A. (2014). How partial reinforcement of food cues affects the extinction and reacquisition of appetitive responses. A new model for dieting success? Appetite, 81, 242-252.

van den Akker, K., Havermans, R. C., \& Jansen, A. (2015). Effects of occasiona reinforced trials during extinction on the reacquisition of conditioned responses to food cues. Journal of Behavior Therapy and Experimental Psychiatry, 48, 50-58.

van den Akker, K., Jansen, A., Frentz, F., \& Havermans, R. C. (2013). Impulsivity makes more susceptible to overeating after contextual appetitive conditioning. Appetite, 70, 73-80. http://dx.doi.org/10.1016/j.appet.2013.06.092.

WHO. (2014). The challenge of obesity - quick statistics. from http://www.euro.who. int/en/health-topics/noncommunicable-diseases/obesity/data-and-statistics. 